\title{
Barreiras às novas formas de coordenação no agrossistema do caju na região nordeste, Brasil
}

\author{
Barriers to new coordination forms in the cashew \\ nut agricultural system in northeast of Brazil
}

\author{
Hildo Meirelles de Souza Filho ${ }^{1}$ \\ Carlos Enrique Guanziroli ${ }^{2}$ \\ Adelson Martins Figueiredo ${ }^{1}$ \\ Aírton Saboya Valente Júnior ${ }^{3}$
}

\begin{abstract}
Resumo: Embora a produção brasileira de amêndoa de castanha-de-caju tenha crescido nos anos 2000, sua participação no mercado internacional reduziu-se, revelando perda de competitividade desse agrossistema. A produtividade na produção rural é baixa e subsiste uma antiquada estrutura de governança das relações entre produtores, intermediários e processadores de castanha em casca. Novas formas de coordenação estão sendo testadas, mas ainda não foram capazes de substituir a antiga. O objetivo desse artigo é identificar o conjunto de barreiras à transformação dessa estrutura. O referencial teórico adotado encontra-se fundamentalmente na Economia de Custos de Transação. Para investigação empírica, adotou-se o método de pesquisa rápida (rapid appraisal), compreendendo entrevistas junto a uma amostra não probabilística de agentes da cadeia nos estados do Ceará, Piauí e Rio Grande do Norte. Os resultados mostram que há resiliência da estrutura de governança antiga, a qual está assentada na funcionalidade e capacidade de reação dos intermediários. Assim, a estratégia de mudança cautelosa das empresas processadoras é, por um lado, racional diante de grandes incertezas, e, por outro, lenta diante das transformações do mercado internacional.
\end{abstract}

Palavras-chave: Sistemas agroindustriais. Coordenação. Castanha de caju. Brasil.

\begin{abstract}
Although the Brazilian production of cashew nuts has increased in the years 2000, its international market-share has decreased revealing competitiveness loss of this agri-system. Agricultural yields are low and a traditional governance structure among farmers, intermediaries, and cashew nut processing industries still subsists. New coordination forms have been tested, but they have not been able to substitute the old one. The objective of this article is the identification of barriers to the changes of this structure. The Economy of Transaction Cost is the theoretical approach adopted. For empirical investigation, a rapid appraisal method was adopted comprising interviews with stakeholders in the states of Ceará, Piauí, and Rio Grande do Norte. The results showed that resilience is remarkable in the old structure, which is underpinned in the functionality and capacity of reaction of intermediaries. Therefore, the cautious strategy adopted by the cashew nut processing industries is, on one hand, rational in the face of uncertainties, and, on the other hand, slow in the face of the international market changes.
\end{abstract}

Keywords: Agri-systems. Coordination. Cashew nuts. Brazil.

\section{Introdução}

A cajucultura comercial foi implantada no Nordeste na década de 1970 com apoio da SUDENE. Utilizaram-se na época dois mecanismos de incentivo fiscal: o Fundo de Investimentos Setoriais para reflorestamento com árvores de caju e o Fundo de Investimentos do Nordeste para o desenvolvimento da indústria processadora de castanha. Foi com base nesses incentivos que se implantaram aproximadamente
300 mil ha de caju gigante (que nos anos 2000 começaram a dar sinais de esgotamento) e as 10 grandes indústrias processadoras de Fortaleza, Teresina e Mossoró.

Em seu contexto mais amplo, o sistema agroindustrial do caju compreende um conjunto de atividades relacionadas com o processamento da castanha, do pedúnculo e a própria venda do caju in natura

\footnotetext{
${ }^{1}$ Universidade Federal de São Carlos - UFSCar, Rodovia Washington Luís, km 235, SP 310, CEP 13565-905, São Carlos - SP, Brasil

${ }^{2}$ Universidade Federal Fluminense - UFF, Rua Miguel de Frias, 9, Icaraí, CEP 24220-900, Niterói, Rio de Janeiro - RJ, Brasil

${ }^{3}$ Banco do Nordeste do Brasil - BNB, C P 628, CEP 60035-210, Fortaleza, Ceará, Brasil

Recebido em 29/6/2009 — Aceito em 21/5/2010
}

Suporte financeiro: Instituto Interamericano de Cooperação para Agricultura e Banco do Nordeste do Brasil, Projeto BRA/ IICA/03/008 - "Cooperação para o Fortalecimento da Capacidade Técnica, Institucional e Operacional do Banco do Nordeste". 
(Figura 1). Do processamento da castanha em casca (fruto verdadeiro), resulta a Amêndoa de Castanha-deCaju (ACC) e o Líquido da Castanha-de-Caju (LCC), ambos de grande valor comercial. Do pedúnculo, são produzidas as bebidas (notadamente o suco e a cajuína) e outros produtos (principalmente doces e ração animal). O caju é ainda vendido como fruto de mesa. Entretanto, estima-se que mais de $90 \%$ do pedúnculo é desperdiçado, ou seja, é um subproduto pouco aproveitado na produção de ACC e LCC.

Esse artigo trata exclusivamente das atividades relacionadas à produção de $\mathrm{ACC}$, que é o principal produto gerado por todo esse agrossistema. A ACC resulta do processamento da castanha-do-caju em casca, cujas etapas podem variar segundo o tamanho das unidades, mas que em seu contexto básico são as seguintes: secagem, limpeza, autoclavagem, corte, despeliculagem, classificação, torra, salga e embalagem (BRASIL, 2003). Após o processamento, a ACC é vendida tanto no mercado externo, para o qual foi mais de $90 \%$ da produção em 2007, e para o mercado doméstico.

No triênio 2004/2005/2006, a produção anual média brasileira de castanha-de-caju em casca foi de 195 mil toneladas, distribuída majoritariamente nos estados do Ceará (48\%), Rio Grande do Norte (22\%) e Piauí (19\%) (BRASIL, 2008b). Nesse mesmo período, as exportações brasileiras de ACC foram de US\$ 187 milhões (BRASIL, 2008a). Em 2006, as exportações mundiais de ACC alcançaram
US\$ 1,3 bilhão, sendo lideradas pela Índia (39\% do volume total), pelo Vietnam (29\%) e pelo Brasil (15\%) (COMTRADE, 2008). Destaca-se o enorme crescimento das exportações do Vietnam, que desde o início dos anos 2000 deslocou o Brasil da segunda posição.

Vietnam e Índia, além de serem grandes produtores de castanha e ACC, bem como grandes exportadores de ACC, estão entre os maiores importadores de castanha. Em 2006, esses dois países foram responsáveis por $88 \%$ das importações mundiais, destacando-se a Índia com 77\% (COMTRADE, 2008). Os principais fornecedores de castanha são os países africanos e a Indonésia, que abastecem principalmente a indústria processadora da Índia.

O crescimento da indústria processadora na África tem se estabelecido como uma ameaça para a indústria indiana não apenas devido ao seu possível crescimento no mercado internacional de ACC mas também pela redução das exportações africanas de castanha. Sem o fornecimento africano, a sobrevivência da indústria indiana de ACC passa a depender do crescimento da produção doméstica de castanha. Outra ameaça à indústria indiana, e também à indústria brasileira, é o crescimento tanto da produção de castanha quanto da capacidade de processamento do Vietnam, onde os custos de produção são baixos devido à elevada produtividade e baixa remuneração da mão-de-obra envolvida, a energia é barata e há incentivos governamentais à implantação de unidades

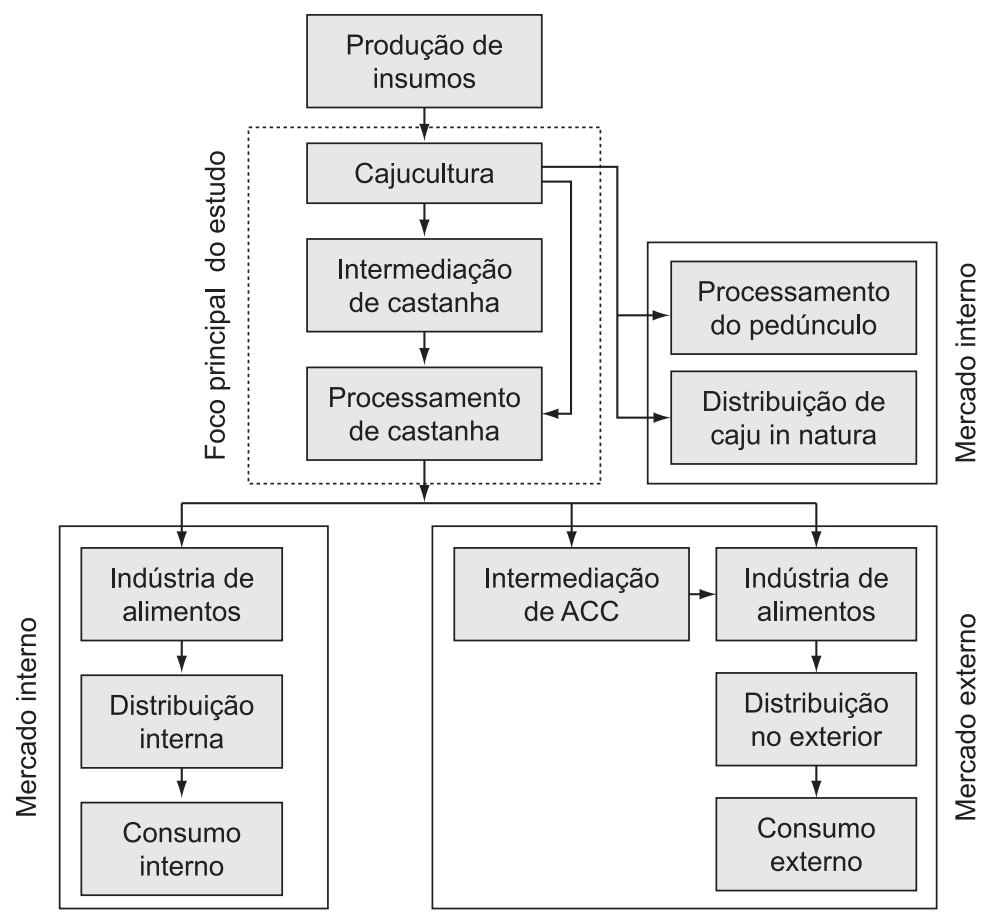

Figura 1. Agrossistema do caju. Fonte: Elaborado pelos autores. 
de processamento modernas. Uma das razões pelas quais os importadores têm aumentado suas compras de processadores do Vietnam está no fato de que as novas fábricas vietnamitas adotam padrões de qualidade reconhecidos, como certificação ISO (International Organization for Standardization). A outra razão é que a castanha vietnamita tem atendido melhor a padrões de demanda em termos de cor, umidade, aroma e percentual de castanhas quebradas (HARILAL et al., 2006).

De fato, há quatro fatores determinantes de mudanças no mercado de ACC que afetaram o agrossistema brasileiro; três dizem respeito ao mercado externo de ACC e um ao mercado doméstico de castanha em casca (INSTITUTO INTERAMERICANO DE COOPERAÇÃO PARA AGRICULTURA - IICA; BRASIL, 2008). O primeiro fator do mercado internacional de ACC está relacionado ao crescimento da produção no Vietnam, cujas bases de produção são novas e sustentadas por forte apoio governamental e baixo custo da mão-de-obra. Os novos exportadores do Vietnam têm ganhado mercados do Brasil e da Índia, comprimindo as margens dos concorrentes e impondo a necessidade de reestruturação produtiva nesses dois países.

Como segundo fator do mercado internacional tem-se observado forte pressão por parte das grandes redes de supermercados, principalmente europeias, no sentido de reduzir as margens dos agentes à montante da cadeia. A reação das indústrias alimentícias e dos processadores tem sido não apenas reduzir suas próprias margens mas também eliminar intermediários de castanha em casca e brokers de ACC. Acompanhando esse movimento está o terceiro fator do mercado internacional, que é a demanda crescente por padrões superiores de qualidade da ACC; tanto em termos de atributos de qualidade do produto quanto em termos de alimento seguro. Esses três fatores impõem reestruturação na governança das cadeias de suprimento, que implicam em redução da intermediação, criação de mecanismos de incentivo à produção de baixo custo, no campo e no processamento, e elevação da qualidade castanha em casca.

Finalmente, o quarto fator a considerar está relacionado ao envelhecimento dos cajuais no Brasil e, portanto, o risco crescente de insuficiência de matéria-prima no mercado doméstico, o que implica não apenas na necessidade de reestruturação para aumentar a produtividade e a qualidade mas também na de expansão da área com plantios novos. A produção brasileira de castanha-de-caju em casca não acompanhou o ritmo de crescimento da demanda internacional, mostrando fortes restrições da produção no campo, que reduziram a competitividade do agrossistema.
Diante desses condicionantes, algumas iniciativas têm sido tomadas por grandes empresas exportadoras de ACC para ampliar sua rede de fornecedores e a qualidade da castanha-de-caju brasileira tais como: contratação de agentes locais exclusivos para compra de castanha; construção de central de recebimento localizada em zona de concentração de produtores de castanha de boa qualidade; ofertas de compra junto a associações de produtores e assentamentos da reforma agrária; concurso para premiação de produtores; palestras para corretores e produtores e contratação de agentes para identificar novos fornecedores.

Em que pesem as iniciativas, existem elementos constitutivos da estrutura de governança dominante desse sistema agroindustrial que bloqueiam mudanças mais radicais. Esses elementos estão relacionados à coordenação entre os elos/agentes, particularmente na determinação de funções, margens e distribuição de ganhos. Por exemplo, é comum haver acusações por parte dos produtores e suas organizações de que intermediários e processadores utilizam seu poder de mercado para apropriar-se de uma fatia cada vez maior da renda gerada no agrossistema. Por outro lado, processadores reclamam da qualidade da castanha fornecida pelos produtores.

Embora estudos sobre a cadeia do caju no Brasil tenham contribuído para a compreensão do seu funcionamento (FIGUEIREDO JUNIOR, 2006; LEITE; PESSOA, 1996; NASSAR; MARINO; HERRMANN, 2001; NASSAR et al., 2000), a maioria dedica-se à descrição dos fluxos de matérias-primas, produtos e financeiros. Apenas Nassar, Marino e Herrmann (2001) tratam da estrutura de governança sob a ótica da Economia dos Custos de Transação e indicam a impossibilidade da adoção de um sistema de incentivos na relação entre produtores de caju e seus compradores dentro do padrão vigente. $\mathrm{O}$ presente artigo pretende contribuir para esse debate por meio da investigação da estrutura de governança existente e da identificação de barreiras à adoção de novas formas de coordenação.

\section{Referencial teórico}

A análise realizada neste artigo faz uso de aportes teóricos da Nova Economia Institucional (NEI) e da Economia dos Custos de Transação (ECT). A NEI contrapõe-se à teoria microeconômica neoclássica afirmando não ser possível o funcionamento automático do mercado e que este não opera somente em função do mecanismo de preços. Em outras palavras, de acordo com a NEI, o mercado não é capaz de funcionar sozinho. Como questiona COASE (1937), se o mercado pode funcionar apenas pelo mecanismo de preços, como afirmam os neoclássicos, por que existem as organizações? Assim, a NEI tem como objetivo identificar qual a melhor forma de organização das transações econômicas. Para ela, diferentes 
configurações alteram as condições para a alocação desses recursos. Nesse caminho analítico, a NEI compõe o conjunto de conceitos utilizado para estudo de estruturas de governança e de coordenação de cadeias produtivas a canais de distribuição.

A Economia dos Custos de Transação parte do pressuposto de que a questão da organização econômica é, antes de tudo, um problema de governança. Neste sentido, pretende explicar as diferentes formas organizacionais que existem no mercado e seus arranjos contratuais, destacando o ambiente institucional e sua interação com as organizações. De acordo com a ECT, existem diferentes estruturas de governança passíveis de serem formadas e os agentes devem buscar estruturas de governança que possibilitem a redução dos custos de transação. Esses últimos são definidos como

[...] aqueles a que estão sujeitas todas as operações de um sistema econômico e [...] surgem devido ao custo de se mensurar as múltiplas dimensões valorizadas incluídas na transação (geralmente os custos da informação) e devido ainda aos custos de execução contratual (NORTH, 1994, p. 33).

A economia, segundo essa corrente, vai além dos limites da unidade de produção, de modo que as relações organizacionais influenciam no direcionamento dos recursos.

Diversos autores deram continuidade a essa linha de raciocínio e desenvolveram estudos sobre formas de coordenação e suas implicações para a eficiência econômica. Dentre eles destacam-se os trabalhos de Williamson (1985, 1991) e Ménard (2004).

Williamson (1985) propõe três formas básicas de governança:

i. Mercado clássico (spot) - forma adaptada de transação não específica, onde não há esforço para sustentar a relação. Nesse formato, a avaliação da relação pelas partes é feita mediante consultas à sua própria experiência. É o caso que mais se aproxima do mercado de concorrência pura.

ii. Formas híbridas - na observância de especificidade de ativos mais elevada e de maior recorrência das transações, relações de confiança podem ser construídas. Nesse caso, não se verificam incentivos capazes de trazer a transação entre os agentes para dentro da firma. Assim, existe elevado interesse dos agentes em cumprir o contrato.

iii. Integração vertical ou hierarquia - trata-se da própria integração vertical, necessária para transações não ocasionais e na presença de ativos altamente específicos. Nesse caso, as transações entre agentes são trazidas para dentro da hierarquia da firma.

A ênfase dada por Williamson na análise dos arranjos trouxe à tona estruturas que se encontravam entre o mercado e a hierarquia, as quais foram tratadas por estruturas híbridas. Em seus estudos, o autor se convenceu de que as formas híbridas eram muito mais comuns do que os modelos originalmente empregados (WILLIAMSON, 1985).

Ménard (2004) alerta para a necessidade de construção de uma teoria que explique as estruturas que se situam entre o mercado e a hierarquia, ainda que as transações envolvidas nessas estruturas relacionem-se a agentes totalmente independentes entre si, mas que atuam conjuntamente em algum tipo de negócio. Para ele, há uma grande variedade de arranjos nas relações entre empresas, as quais se ajustam sob pouca influência do mecanismo de preços, compartilhando tecnologias, capital, produtos ou serviços, mas sem que haja integração total entre as mesmas. Estes seriam os elementos mínimos necessários para caracterizar estruturas híbridas de coordenação.

Ménard (2004) coloca a união dos esforços como uma propriedade comum entre as estruturas híbridas. Independente do seu formato, a coordenação das atividades basear-se-ia na cooperação entre as partes e no compartilhamento de decisões importantes, como sobre investimentos a serem realizados. Por um lado, essa união cria a cultura da busca conjunta por maior desempenho e rentabilidade para o conjunto, por outro lado, uma má distribuição de tarefas e ganhos pode facilmente gerar conflitos que desestabilizem o arranjo.

As formas híbridas existem porque o mercado é insuficiente para lidar adequadamente com os recursos e as competências nos sistemas produtivos adaptáveis, enquanto a hierarquia torna esses mesmos sistemas pouco flexíveis e cria incentivos fracos contra o oportunismo.

Ménard (2004) alerta para o fato de que ações conjuntas entre parceiros colocam o arranjo sob risco constante de oportunismo. Para reduzir o problema, três fatores devem ser observados. O primeiro diz respeito à escolha criteriosa dos agentes que irão compor o grupo. O segundo fator está relacionado com a escolha de um arranjo tal que equilibre a independência da organização com a necessidade de agir como um bloco uniforme. Nesse sentido, a estrutura de governança das transações deve contemplar mecanismos de controle não tão rígidos quanto a hierarquia dentro de uma empresa nem tão fracos quanto no mercado spot. Em terceiro lugar, o fluxo de informações entre os agentes é condição essencial para o funcionamento do coletivo. Desenvolver um sistema de informações não só alicerça a forma híbrida de coordenação como também contribui para reduzir assimetria de informações, especialmente quando 
entre os fornecedores há um agente coordenador que detém acesso direto aos compradores, podendo obter informações privilegiadas e que não seriam repassadas na integra aos parceiros.

As relações dependem de fatores como cooperação e coordenação. A questão por trás dessas características das estruturas híbridas acaba sendo como coordenar os agentes visando garantir a cooperação entre eles sem elevar os custos operacionais e sem que se percam as vantagens da autonomia e das decisões descentralizadas.

Os contratos seriam outro elemento comum entre as estruturas híbridas, pouco dependendo do nível de formalidade da relação. Contratos estabelecem caminhos para se regular as transações, criando reciprocidade entre os agentes. Sua presença traz vantagens mas também riscos. Dentre as vantagens estão a transferência de conhecimento e o compartilhamento de recursos (financeiros, de equipamentos, etc.) e de competências. No sentido oposto, a incompletude a que estão sujeitos os contratos aumenta as chances de renegociações não previstas e os riscos de oportunismo, especialmente quando estão presentes atributos como especificidade de ativos e incerteza.

Outro elemento que surge na literatura sobre formas híbridas é a importância da pressão competitiva na modelagem dos arranjos. Essa pressão opera em duas direções. Primeiro, os agentes competem entre si, mesmo sendo participantes do mesmo arranjo. Essa característica é mais presente quando envolve o mesmo mercado consumidor. Fornecedores de uma empresa podem participar da mesma rede e, simultaneamente, competir entre si por uma maior participação no abastecimento. Segundo, as próprias cadeias ou redes híbridas competem entre si, tendo ou não elementos comuns entre elas. Isso ocorre frequentemente na produção agroindustrial, onde cadeias de abastecimento são supridas muitas vezes por um mesmo grupo de fornecedores, ou por uma parte deles, e têm que competir entre si pelo mercado consumidor.

No caso de arranjos em que a especificidade dos ativos é baixa ou moderada, alguns agentes podem migrar para outras cadeias visando melhorar sua posição competitiva e, com isso, aumentar a instabilidade das estruturas. Aliás, é exatamente em mercados altamente competitivos, onde a incerteza é uma constante, que estão presentes grande número de exemplos de formas híbridas de coordenação, por favorecerem a união de esforços e flexibilidade. Por isso, adotar mecanismos que permitam monitorar os agentes e prever potencial comportamento oportunista é fundamental para manter a força da estrutura.

Numa visão geral, percebe-se que arranjos híbridos surgem porque os parceiros encontram vantagens em compartilhar investimentos. Ao fazer isso, eles aceitariam como contrapartida a mútua dependência. Em vista disso, o grau de dependência será condicionado pela capacidade de os agentes elaborarem mecanismos capazes de assegurar que os investimentos sejam feitos, de monitorá-los e de determinar como os ganhos esperados serão compartilhados. Para isso, é necessário garantir a estabilidade da relação e reduzir o oportunismo.

O desafio da estrutura de governança na coordenação dos agentes econômicos envolvidos é, portanto, definir e operar mecanismos (incentivos econômicos, regulatórios e contratuais) que reduzam conflitos, contradições e custos de transação ao longo de toda a cadeia, e, ao mesmo tempo, reforcem os incentivos para que cada um dos agentes atue em conformidade com os objetivos estratégicos dos atores líderes. Ações melhor coordenadas em função da maior interação entre agentes têm reflexos diretos sobre o abastecimento, pois diminuem o tempo de resposta e contribuem para garantir a disponibilidade de produtos com preço e qualidade na quantidade demandada pelo consumidor.

\section{Hipóteses}

O marco teórico acima fornece elementos para a investigação da estrutura de governança existente na cadeia da ACC e a identificação de barreiras à adoção de novas formas de coordenação. A hipótese fundamental que sustenta a investigação é que, nas condições atuais, a mudança para estruturas híbridas, que contemplem mecanismos de controle não tão rígidos quanto a hierarquia nem tão fracos quanto os que existem atualmente no mercado spot, e que transmitam incentivos para os produtores rurais, encontrará fortes barreiras. Essas barreiras seriam determinadas por três fatores: a baixa especificidade de ativos ainda predominante na produção rural; presença de uma rede de intermediários de castanha em casca que estabelecem relações de dependência com os produtores rurais e possuem grande capacidade de resistir a eventuais concorrentes; e elevados investimentos necessários para estabelecer uma nova estrutura sob coordenação direta das empresas processadoras, cujo retorno apresenta elevado risco devido à capacidade de resistência dos intermediários e a baixa especificidade dos ativos na produção no campo.

\section{Metodologia}

Na investigação empírica desse trabalho adotou-se o enfoque metodológico conhecido como "método de pesquisa rápida" (rapid assessment ou quick appraisal). Essa metodologia tem sido aplicada para responder às desvantagens das abordagens tradicionais de pesquisa nos casos em que há limitação de tempo ou de recursos financeiros (KUMAR, 1993; SILVA, SOUZA FILHO, 2007). As informações podem ser obtidas por meio formal ou informal, ou pela 
combinação dos dois. Valorizam-se as informações de fontes secundárias, que devem ser levantadas em etapa inicial da pesquisa. Adicionalmente, são realizadas entrevistas com poucos agentes-chave da cadeia. Entenda-se por agentes-chave aqueles que têm representatividade na cadeia. Incluem-se empresas do ramo, associações e órgãos representantes da cadeia, órgãos vinculados ao poder público. É comum os agentes terem pouco tempo disponível para entrevistas, portanto as questões aplicadas devem abranger apenas os aspectos que não podem ser respondidos por fontes secundárias de dados.

As informações primárias foram coletadas por meio de entrevistas junto a uma amostra não probabilística de agentes da cadeia. Essas entrevistas foram conduzidas nos meses de agosto e setembro de 2008, com 17 produtores, 9 corretores, 8 diretores de empresas processadoras, 6 diretores/gerentes de minifábricas/cooperativas e 4 representantes e técnicos de organizações da cadeia (Sindicato das Indústrias de Beneficiamento da Castanha-deCaju e Amêndoas Vegetais do Estado do Ceará, Sindicato dos Produtores de Caju do Ceará, Embrapa Agroindústria Tropical e Empresa de Assistência Técnica e Extensão do Ceará). Foram aplicados questionários semiestruturados, segundo o tipo de agente (produtor, corretor e diretores de empresa). Entrevistas não estruturadas foram realizadas junto aos representantes e técnicos das organizações da cadeia. As entrevistas foram conduzidas nos Estados de Ceará, Rio Grande do Norte e Piauí por equipes formadas por consultores do Instituto Interamericano de Cooperação para Agricultura e técnicos do Banco do Nordeste do Brasil.

\section{Resultados e discussões}

\subsection{Caracterização dos agentes}

O foco principal do presente estudo está nas transações entre produtores de castanha-de-caju em casta, intermediários e processadores. Ainda nas propriedades rurais, a castanha é separada do pedúnculo, secada ao sol e vendida, em sua grande maioria, para intermediários, que repassam para a indústria processadora. Apenas grandes produtores, devido a sua capacidade de obter maior escala na entrega, conseguem vender castanha diretamente para a indústria de processamento.

A cajucultura tem sido desenvolvida tanto em pequenas quanto em grandes e médias explorações rurais, existindo forte heterogeneidade em termos de nível tecnológico (Tabela 1). Destacam-se os sistemas voltados para o cultivo tradicional do cajueiro gigante e aqueles direcionados para o cultivo de variedades recentes de cajueiro anão, desenvolvidas pela EMBRAPA. Em meados dos anos 2000, a maioria das plantações de cajueiro gigante, resultado dos programas de incentivos governamentais dos anos 1970, encontrava-se em fase final de seu ciclo de produção, muitas com cerca de 30 anos. As plantações de cajueiro anão são recentes e têm sido incentivadas como alternativa de reposição dos velhos cajuais.

O processamento da castanha do caju é realizado por minifábricas (independentes ou em sistema cooperativo) e grandes unidades industriais, mas está fortemente concentrado nessas últimas. Quase todo o processamento é realizado no Ceará, que absorve parcela significativa da produção de castanha em casca proveniente do Piauí e Rio Grande do Norte. Em 2008, a capacidade de processamento das nove maiores empresas estava estimada em $295 \mathrm{mil}$ toneladas (entrevistas e Sindicato das Indústrias de Beneficiamento de Castanha-de-Caju e Amêndoas Vegetais do Estado do Ceará - SINDICAJU). A capacidade de processamento das quatro maiores empresas equivalia a $53 \%$ do total registrado de entrada de matéria-prima na safra 2006/2007. A maioria das grandes unidades de processamento é controlada por grupos econômicos nacionais com diversificação de investimentos em outras atividades agropecuárias e ramos industriais. Apenas uma dessas empresas produz uma quantidade expressiva de castanha-de-caju para atender suas necessidades de beneficiamento (Tabela 2).

Os principais compradores no mercado internacional são os brokers e a indústria de alimentos. Esta última realiza a torra e a salga para venda no mercado de snacks, bem como utiliza o produto na composição de outros alimentos (panificação e confeitaria, tais como doces, bolos, biscoitos, sorvetes etc.). No mercado interno, a ACC tem destino semelhante, mas

Tabela 1. Número de produtores por estrato de área.

\begin{tabular}{crrr}
\hline Número de produtores & Piauí & Ceará & \multicolumn{1}{c}{ RN } \\
\hline Menores de 5 há & 9,325 & 27,821 & 10,803 \\
De 5 a 20 há & 7,963 & 15,999 & 6,543 \\
De 20 a 100 há & 8,455 & 10,127 & 4,950 \\
Mais de 100 há & 3,190 & 3,639 & 1,247 \\
Total & 28,935 & 57,591 & 23,549 \\
\hline
\end{tabular}

Fonte: Censo agropecuário IBGE (1996). 
a presença de intermediários é menos proeminente e as unidades de processamento domésticas (grandes empresas e minifábricas) assumem as etapas de torra e salga. Cabe ainda destacar que a comercialização de ACC é realizada sob um sistema de classificação internacional, estabelecido pela Association of Food Industries, Inc. (AFI), que permite a diferenciação de preços da ACC segundo o tamanho, a coloração e os defeitos (Quadro 1). As transações entre a indústria produtora de ACC e seus clientes ocorrem tanto sob contratos formais quanto via mercado spot. Entretanto, essas transações não são o foco principal desse artigo.

\subsection{Descrição das transações de castanha-de-caju em casca e seus principais condicionantes}

No Brasil, a comercialização da castanha-de-caju em casca ocorre fundamentalmente entre produtores rurais, intermediários (também chamados de corretores nas zonas produtoras) e processadores. Dos 18 produtores entrevistados, 17 vendiam para corretores e 1 era também corretor; nenhum vendia diretamente para a agroindústria processadora. Oitenta a $100 \%$ da quantidade de castanha adquirida pelas oito empresas que respondiam por aproximadamente $75 \%$

Tabela 2. Capacidade instalada das maiores empresas de processamento de castanha-de-caju, Brasil.

\begin{tabular}{|c|c|c|c|c|c|c|}
\hline Nome da empresa & & $\begin{array}{c}\text { Capacidade } \\
\text { instalada } \\
\text { em } \\
\text { toneladas }\end{array}$ & $\begin{array}{c}\% \text { da } \\
\text { capacidade } \\
\text { no total das } \\
\text { maiores } \\
\end{array}$ & $\begin{array}{c}\% \\
\text { Acumulada }\end{array}$ & $\begin{array}{c}\text { \% da entrada } \\
\text { registrada } \\
\text { de castanha } \\
2006 / 2007\end{array}$ & $\begin{array}{c}\% \\
\text { Acumulada }\end{array}$ \\
\hline $\begin{array}{l}\text { 1. IRACEMA- Indústria e Comércio } \\
\text { de Castanhas de Caju Ltda. }\end{array}$ & $\mathrm{CE}$ & 65,000 & $22 \%$ & $22 \%$ & $20 \%$ & $20 \%$ \\
\hline 2. CASCAJU Agroindustrial S.A & $\mathrm{CE}$ & 40,000 & $14 \%$ & $36 \%$ & $12 \%$ & $32 \%$ \\
\hline $\begin{array}{l}\text { 3. USIBRAS - Usina Brasileira de } \\
\text { Óleos e Castanha Ltda. }\end{array}$ & $\mathrm{CE}$ & 35,000 & $12 \%$ & $47 \%$ & $11 \%$ & $43 \%$ \\
\hline $\begin{array}{l}\text { 4. AFICEL - A. Ferreira Ind. } \\
\text { Comércio e exportação Ltda. }\end{array}$ & $\mathrm{RN}$ & 32,000 & $11 \%$ & $58 \%$ & $10 \%$ & $53 \%$ \\
\hline $\begin{array}{l}\text { 5. Companhia Brasileira de } \\
\text { Resinas - RESIBRAS }\end{array}$ & $\mathrm{CE}$ & 30,000 & $10 \%$ & $68 \%$ & $9 \%$ & $62 \%$ \\
\hline 6. Amêndoa do Brasil Ltda. & $\mathrm{CE}$ & 30,000 & $10 \%$ & $79 \%$ & $9 \%$ & $71 \%$ \\
\hline $\begin{array}{l}\text { 7. Cia. Industrial de Óleos do } \\
\text { Nordeste- CIONE }\end{array}$ & $\mathrm{CE}$ & 25,000 & $8 \%$ & $87 \%$ & $8 \%$ & $79 \%$ \\
\hline 8. Irmãos Fontenele & $\mathrm{CE}$ & 20,000 & $7 \%$ & $94 \%$ & $6 \%$ & $85 \%$ \\
\hline $\begin{array}{l}\text { 9. Europa Indústrial de Castanhas } \\
\text { Ltda. }\end{array}$ & PI & 18,000 & $6 \%$ & $100 \%$ & $6 \%$ & $91 \%$ \\
\hline Total & & 295,000 & $100 \%$ & & & \\
\hline $\begin{array}{l}\text { Entrada registrada de castanha } \\
\text { (matéria-prima) safra 2006/2007 } \\
\text { (Teixeira. 2008) }\end{array}$ & & 325,000 & & & & \\
\hline $\begin{array}{l}\text { Média da produção brasileira de } \\
\text { castanha em } 2007 \text { (IBGE) }\end{array}$ & & 190,968 & & & & \\
\hline
\end{tabular}

Fonte: Entrevistas no Sindicato das Indústrias de Beneficiamento de Castanha de Caju e Amêndoas Vegetais do Estado do Ceará SINDICAJU e nas empresas.

Quadro 1. Classificação da ACC no mercado internacional.

\begin{tabular}{|lcl|}
\hline Tipo & Denominação & \multicolumn{1}{c|}{ Denominação em português e características } \\
\hline SLW & Special Large Whole & Inteira super especial, até 180 amêndoas por libra peso \\
LW & Large Whole & Inteira especial, entre 181 a 210 amêndoas por libra peso \\
W & Whole & Inteira, entre 211 a 450 amêndoas por libra peso \\
SW & Small Whole & Inteira, mais de 450 amêndoas por libra peso \\
B & Butts & Batoques, amêndoas quase inteiras com pequenas fraturas transversais \\
SB & Small Butts & Batoques com menos da metade da amêndoa \\
S & Splits & Metade (bandas), cotilédones separados, inteiros, sem fraturas \\
Outros* & Diversos & Pedaços, grânulos, resíduos, xerém e farinha \\
\hline
\end{tabular}

Fonte: AFICEL, http://www.aficel.com.br/pt/nomenclatura.php, acessado em 16 out. 2008. 
da capacidade instalada nos três estados provinha de corretores. Essas empresas compraram diretamente de produtores apenas $8,8 \%$ do volume total do que processavam. Transações diretas entre produtores e unidades processadoras ocorrem com mais frequência quando essas unidades pertencem a cooperativas/ associações de produtores e miniusinas, como no caso de três cooperativas/associações e duas miniusinas da amostra, que declararam comprar $100 \%$ das castanhas diretamente de produtores. Entretanto, a capacidade instalada dessas unidades correspondeu a apenas $1 \%$ da capacidade do conjunto das empresas da amostra. Ainda assim, uma das miniusinas declarou comprar $100 \%$ das castanhas junto a corretores.

Portanto, há dois tipos de transação predominantes: produtores rurais-corretores e corretores-processadores (T1 e T2, na Figura 2). Essas transações ocorrem sob condições próximas do que Williamson (1996) classificou como mercado clássico, em contraposição a formas híbridas mais conhecidas (por exemplo, contratos formais com cláusulas de precificação, quantidade e qualidade) e hierárquicas (integração vertical). As principais características das transações no mercado clássico são a baixa especificidade dos ativos e a ausência de contratos formais. No caso de produtos agroindustriais sujeitos às oscilações de oferta, o mercado clássico é ainda caracterizado por alto grau de incerteza com relação ao comportamento dos preços. Todas essas características estão presentes nas transações com castanha-de-caju em casca. Entretanto, no mercado clássico, os agentes são independentes e as transações resolvem-se em um único instante no tempo, em um mercado tipicamente esporádico, onde não há obrigatoriedade de compra futura. Essas três características não estão presentes em seu estado puro na comercialização da castanha-de-caju em casca, como se verá adiante. Por isso, embora próximo, não se pode assumi-la como uma governança de mercado clássico em seu estado puro.

As transações de compra e venda entre corretores e produtores, T1, seguem o ritmo da colheita de castanha no campo. Iniciam-se em setembro, atingem seu pico em outubro/novembro, quando a colheita no Ceará é mais intensa, e declinam em dezembro. As transações de compra e venda entre corretores e processadores, T2, ocorrem com maior frequência também nesse período, mas também no período de entressafra, dado que os corretores formam estoques especulativos, como será visto adiante.

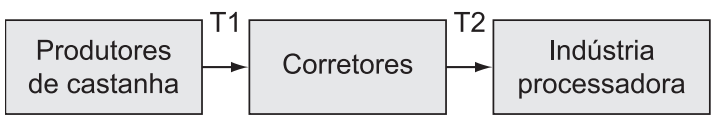

Figura 2. Principais transações no mercado de castanha em casca no Brasil.
As aquisições de castanha em casca são realizadas pelos corretores junto aos produtores rurais da região circunvizinha ao seu ponto de compra, podendo abranger mais de um município. Na amostra pesquisada, a distância média entre os produtores e os depósitos dos corretores foi de $18 \mathrm{~km}$, com um desvio-padrão de $18 \mathrm{~km}$. O ponto de compra do corretor está localizado em zona urbana, geralmente em conjunto com o comércio varejista/atacadista do corretor. O número médio de produtores por corretor, em sete corretores da amostra, foi de 251, com desvio-padrão de 349 . Um grande corretor adquiria castanha em casca de 1000 produtores. Para transportar a castanha comprada, a maioria dos corretores utiliza frota própria e/ou contrata frete de terceiros. Estima-se que, para formar uma "carrada" - 20 toneladas de castanha, capacidade de carga de um caminhão -, seja necessário coletar castanha em casca de 20 produtores, estimando-se uma média de uma tonelada por produtor. Todo o processo de intermediação é absolutamente informal, sem pagamento de impostos.

Três corretores da amostra informaram comprar também castanha de outros corretores. Um deles comprava de 50 outros corretores menores. De fato, apenas esses últimos operam exclusivamente com produtores. Seu ponto de compra está associado à sua bodega, onde vende gêneros de primeira necessidade. Localiza-se notadamente em áreas mais próximas ao produtor, como os vilarejos ou vias de fácil acesso. Pode estar presente também nas feiras. A maioria das transações desses últimos é de pequena escala, envolvendo volumes menores de pequenos produtores e formando partidas maiores ("carradas" de 20 toneladas) para venda a outros corretores ou diretamente para empresas processadoras. Os corretores maiores que compram essa castanha podem ser também fornecedores atacadistas do comércio varejista desse primeiro intermediário. Nesses casos, há transações de troca de castanha por gêneros comercializados na bodega.

Depois de formada uma "carrada" no campo, o caminhão não segue necessariamente para o depósito do corretor. Durante o período mais intenso de colheita, o corretor encaminha a maior parte de suas compras diretamente para a indústria processadora, com a qual pode já ter compromissado a venda.

O transporte e seus custos são absorvidos por $80 \%$ dos corretores entrevistados, seja na venda para a indústria seja na compra junto aos produtores, principalmente quando a coleta é realizada nas propriedades. Quando a compra é realizada junto a outro corretor, a responsabilidade do transporte $\mathrm{e}$ seus custos dependem de negociação estabelecida a cada caso. 


\subsection{A determinação dos preços pagos aos produtores}

Todos os corretores da amostra disseram que obtêm informação sobre o preço da castanha com seu comprador, ou seja, com as unidades de processamento ou com outros corretores. O corretor é um tomador de preço do mercado. Estabelece o seu preço de compra descontando uma margem fixa do que receberá do processador ou de outro corretor. Essa margem, tradicionalmente, gira em torno de 5\% do valor a ser recebido dos processadores, podendo alcançar $10 \%$ para cada transação. A margem bruta média informada pelos corretores da amostra foi de $11 \%$, enquanto a margem líquida média foi de $7 \%$. Por exemplo, na safra 2007/2008, os corretores avaliaram que sua margem, em valores absolutos, esteve entre $\mathrm{R} \$ 0,05$ a $\mathrm{R} \$ 0,10$ por quilo de castanha comprada e vendida. Assumindo um preço de venda ao redor de $\mathrm{R} \$ 1,00 / \mathrm{kg}$, o produtor deve ter recebido entre $\mathrm{R} \$ 0,90$ e $\mathrm{R} \$ 0,95$ por quilo. Dessa forma, as indústrias processadoras informam os preços para os corretores, que por sua vez os informam para os produtores.

$\mathrm{O}$ preço apresenta sazonalidade durante o ano. Em um ano de produção normal, é mais elevado no início da safra, cai no pico e volta a subir no final. Em anos de quebra de safra, como em 2007/2008, os preços podem subir entre o início e o fim do ciclo, na medida em que se percebe que os estoques acumulados serão insuficientes para atender a demanda da indústria. Nesse caso, beneficiam-se todos os agentes que retêm estoques. Entretanto, dentre os 9 corretores da amostra, apenas três declararam possuir estoque - quatro declararam não possuir e os demais não responderam à questão.

Nenhum dos corretores entrevistados estabelecia diferenciação formal de preços por tamanho ou qualidade. Apenas um afirmou que examina o percentual de umidade e recusa o produto caso ela esteja elevada. Argumentam que as empresas processadoras não pagam por essa diferenciação e, portanto, não teriam como estabelecer esse procedimento. Entretanto, essa justificativa não correspondeu exatamente ao verificado junto às empresas processadoras, cooperativas/associações e minifábricas da amostra, dado que $43 \%$ delas informaram fazer algum tipo de classificação para determinar o preço de compra. Mesmo admitindo que um grupo de empresas promova o pagamento por qualidade para os corretores, a concorrência entre eles poderia abortar uma iniciativa isolada. Conforme informado por um corretor, se ele isoladamente adotasse descontos por baixa qualidade, correria o risco de perder o fornecedor para o concorrente. Outra barreira à adoção de diferenciação de preços por qualidade está na baixa escala de comercialização dos pequenos produtores. Para estabelecer uma escala mínima de entrega semanal (ou mesmo quinzenal), digamos um saco, os pequenos produtores teriam que misturar castanhas de baixa qualidade com as de melhor qualidade. De fato, nenhum dos entrevistados separava as castanhas por tamanho e apenas um afirmou que o comprador pagava por melhor qualidade. Nesse caso, para aumentar o volume por entrega, os pequenos produtores teriam que reduzir o número de entregas e aguardar por um período mais longo, ou seja, estocar. Isso ampliaria a espera até o produtor começar a receber. Para pequenos produtores, essa é uma alternativa inviável, dado seu nível de endividamento, como será visto na próxima seção. No caso de produtores com dívidas a pagar junto a corretores, isso pode significar maior gasto com juros e/ou maior resistência dos corretores, que podem não se dispor a esperar para receber o produto. Além disso, $76 \%$ dos produtores entrevistados informaram que a estocagem tem como desvantagem a perda de qualidade - para a maioria deles, perda de qualidade tinha o mesmo significado de perda de umidade ou peso, o que lhes traz prejuízo.

Apesar de não haver um mecanismo formal de diferenciação de preço por tamanho ou qualidade da castanha, é comum a prática dos corretores rejeitarem carregamentos com excesso de impurezas e castanhas danificadas. Entretanto, em anos de escassez de oferta, como 2007/2008, esse tipo de controle tende a ser abandonado.

\subsection{A compra antecipada junto aos produtores}

Todos os corretores da amostra afirmaram que realizam compras com adiantamento de dinheiro para o produtor. As compras realizadas por esse mecanismo de crédito atingiram 54\% do volume total comprado por corretores da amostra; mas há corretores que afirmaram ter realizado $100 \%$ das suas aquisições dessa forma. $\mathrm{O}$ adiantamento em dinheiro aos produtores é largamente utilizado como forma de assegurar suprimento. Trata-se de uma forma de concessão de crédito vinculada à transação de compra e venda de castanha entre corretores-produtores e corretores-processadores. Essa é uma característica da transação que a torna diferente da forma de governança classifica como mercado clássico em seu estado puro.

O corretor concede crédito para os produtores com até 10 meses de prazo, para pagamento com entrega de castanha em casca no período de colheita. Nos meses de junho e julho, que antecedem o início da safra, há forte demanda de crédito por parte dos produtores, que é atendida pelos corretores. Em 2008, os juros cobrados nessas transações variaram entre $1,5 \%$ a $5 \%$ ao mês. 
No pico da colheita, as compras são realizadas semanalmente pelos corretores, que pagam com uma semana de antecedência aos produtores que não realizaram adiantamentos. Nesse caso, a taxa de juros é 0\%. Essa prática é largamente difundida no setor e estabelecida a partir das empresas processadoras. Essas últimas também adiantam, semanalmente, o capital de giro necessário aos corretores, conforme será visto adiante. O nível de inadimplência nas operações de adiantamento de dinheiro aos produtores é pequeno. Segundo informado por alguns corretores é comum uma inadimplência de $1 \%$, que se eleva em anos de frustração de safra, como em 2000, quando um dos corretores apontou inadimplência de 30\% entre aqueles aos quais adiantou dinheiro.

O crédito obtido pelos produtores nos adiantamentos mais longos pode ser utilizado tanto para custeio de cultura de subsistência (notadamente mandioca), quanto para aquisição de gêneros de primeira necessidade. Mesmo em situações em que o produtor tem acesso ao crédito oficial de custeio de culturas de subsistência, ele não deixa de tomar o crédito adicional fornecido pelos corretores dada sua carência de recursos.

Não há prefixação de preço nas transações com adiantamento de dinheiro para os produtores. $\mathrm{O}$ preço é definido sob as condições de mercado no momento da entrega, durante o período de colheita. $\mathrm{O}$ fornecimento de crédito não deixa de ser um mecanismo de fidelização, amarrando a venda ao corretor/emprestador. De fato, $60 \%$ dos corretores da amostra afirmaram utilizar a oferta de adiantamento em dinheiro para obter a fidelidade dos seus fornecedores ou cativar novos. Em regiões mais distantes das empresas processadoras, em que o corretor está menos sujeito à concorrência de outros compradores, o seu poder de barganha aumenta significativamente nas transações com os produtores.

De qualquer forma, a dívida do produtor para com o corretor pode ser paga financeiramente, caso o produtor deseje vender para outro corretor que ofereça melhor preço. Entretanto, essa alternativa poderá ter como consequência maior dificuldade em obter crédito na safra seguinte, sendo pouco utilizada pelos produtores. Dessa forma, estabelece-se um vínculo de dependência entre os agentes, o que torna a transação diferente da forma de governança classificada como mercado clássico e mais próxima da forma híbrida descrita por Williamson (1996) e Ménard (2004).

\subsection{Concorrência no mercado local de castanha}

A transação que envolve a transferência de castanha de produtor para corretor ocorre em um mercado com segmentação regional. Os corretores entrevistados concentram suas compras no próprio município e nos municípios circunvizinhos. Possuem áreas de atuação determinada, em grande medida, pelo conhecimento a respeito das condições de produção local e da rede de fornecedores a eles ligados por relações de crédito e confiança. Essa é a única barreira à entrada mencionada pelas corretores nas entrevistas com corretores. Na prática, podem ocorrer situações extremas, nas quais quem é "de fora" não consegue comprar num município onde não é conhecido.

$\mathrm{Na}$ visão do corretor, a confiança do produtor em relação ao seu comprador de castanha é fundamental. Manifesta-se na hora de pesar o produto: "se é honesto tem uma balança que não mente". Os corretores podem cativar produtores com relações de confiança tal que eles não vendem a outros. $\mathrm{O}$ atendimento personalizado é fundamental: visita semanalmente a propriedade e compra todo o estoque disponível. Para testar essa percepção dos corretores, perguntou-se aos produtores da amostra quais eram os motivos para a escolha do comprador deixando em aberto as possibilidades de resposta. Apenas $24 \%$ deles manifestaram respostas relacionadas a confiança, $47 \%$ responderam que o motivo era o preço.

Entretanto, há relatos de que pequenos corretores que operam em feiras estabelecem barreira à entrada de concorrentes. Se um comprador de castanha que não é da área tentar adquirir diretamente dos produtores que acorrem às feiras, será expulso do mercado pelos corretores ali estabelecidos e obrigado a comprar apenas desses últimos.

Há, portanto, uma regionalização na atuação dos corretores já estabelecidos. Isso não significa um monopólio puro localizado, pois é comum haver mais de um corretor em cada município ou região de produção. Em determinadas regiões, dois ou mais corretores podem dividir sua área de atuação de forma a evitar a competição entre eles. De fato, $70 \%$ dos produtores da amostra afirmaram ter vendido castanha para dois ou mais corretores nas últimas três safras.

Portanto, o mercado local não assume uma única face. As investigações de campo mostraram que em determinadas regiões as barreiras à entrada são mais elevadas, dada a rede mais sólida de confiança e crédito estabelecida entre corretores e produtores. Em outras, suspeitou-se da existência de acordos tácitos de não invasão de área, embora nenhum dos corretores entrevistados o tenha admitido. Há ainda regiões onde, mesmo havendo divisão de área de atuação, as margens não crescem além de um determinado limite, dado que não há fidelidade suficiente para evitar que novos entrantes consigam fazer aquisições a preços melhores do que os já estabelecidos.

A criação de cooperativas de produtores para comercialização e/ou processamento da castanha e as iniciativas de empresas processadoras para comprar diretamente dos produtores tem acirrado a concorrência 
no mercado, em benefício dos produtores. De fato, tanto cooperativas quanto empresas processadoras são vistas como um novo entrante. Nesse caso, observou-se que corretores já estabelecidos procuram deslocá-los do mercado, seja por meio de maior oferta de crédito ao produtor, seja por oferta de melhor preço. Por exemplo, cooperativas de produtores enfrentam dificuldades para manter a fidelidade de seus cooperados porque podem atrasar em até 120 dias o pagamento da castanha recebida para processamento, enquanto os corretores realizam pagamento antecipado ou à vista.

\subsection{Formação de estoques especulativos}

A formação de estoques não é uma prática necessária para a intermediação realizada pelos corretores, dado que é possível obter uma margem líquida apenas formando "carradas" para serem enviadas diretamente para a indústria. Entretanto, os corretores podem adotar a estratégia de formar estoques especulativos, de acordo com sua avaliação a respeito do comportamento futuro do mercado. As percepções a respeito do mercado são formadas antes mesmo do início do período de compra, quanto buscam informação sobre a florescência e as demais condições de produção, tais como incidência de pragas e doenças e as condições climáticas nas diversas regiões produtoras. Essas informações são coletadas por meio de visitas às áreas de produção, contatos com os produtores e as empresas processadoras (compradoras dos grandes e médios corretores). Com base nessas informações e na sua própria expertise, os corretores procuram montar sua estratégia de compra. Por exemplo, no início 2008, os corretores de Serra do Mel perceberam que as chuvas foram escassas, o que lhes indicava que haveria falta do produto e, portanto, decidiram estocar maior quantidade de castanha em casca.

O corretor não formará grandes estoques se sua prospecção demonstrar que a produção será satisfatória. Nesse caso, limita-se a obter margens fixas a partir do giro rápido de seu próprio capital e/ou do capital tomado sob forma de venda antecipada junto às empresas processadoras. A regra é comprar e vender rapidamente. Se a sua prospecção demonstra que a produção do ano-safra será ruim, antecipa-se na formação de estoques enquanto os preços ainda estão baixos. Na medida em que a safra avança, o corretor irá reavaliar sua posição com novas informações, podendo aumentar ou reduzir seus estoques durante todo o período. Em condições normais de mercado, os preços caem durante o pico da colheita e voltam a subir no final. Nesse caso, é ainda vantajosa a formação de estoques no pico da safra, quando haverá pressão de venda.
Segundo dois corretores da amostra, o tempo médio de estocagem é de 6 meses, embora um corretor tenha estimado em 3 meses e outro em 2 semanas. O período de estocagem nas transações especulativas é de aproximadamente 6 meses, mas pode alcançar até 10 meses em anos de grande frustração de safra, conforme observado em 2007/2008. Naquela safra, os estoques operacionais acumulados pela maioria das empresas processadoras esgotaram-se 2 meses antes do início da nova safra. Havia corretores que formaram estoques especulativos e venderam em posição extremamente privilegiada. Em média, formaram estoques pagando $\mathrm{R} \$ 0,90 / \mathrm{kg}$ de castanha em casca, em outubro/novembro, e revenderam a $\mathrm{R} \$ 1,70 / \mathrm{kg}, 10$ meses depois.

As instalações para estocagem são simples, sem qualquer sofisticação tecnológica. Em um galpão, os sacos são empilhados sobre estrados de madeira. $\mathrm{O}$ único equipamento utilizado é uma balança para controle de entrada e saída de estoque. Não há tratamento para conservação do produto, que pode perder entre $2 \%$ a $3 \%$ de umidade durante um período de estocagem de duas semanas. A perda de umidade é um dos maiores custos da estocagem e é considerada na estratégia de formação de estoques.

\subsection{As transações entre corretores e processadores}

Não há laços de fidelidade fortemente estabelecidos nas transações entre corretores e indústrias processadoras, embora $60 \%$ dos corretores entrevistados tenham indicado o adiantamento em dinheiro como uma estratégia utilizada. Um grande corretor afirmou ter realizado todas as suas vendas para quatro grandes empresas processadoras. Corretores de menor porte também vendem para as indústrias processadoras, desde que atendam à escala mínima de entrega, que é de 20 toneladas (uma "carrada").

As transações são realizadas semanalmente, por telefone, com a empresa processadora que oferecer o maior preço. Em sua maioria, as transações iniciam-se com uma oferta de compra antecipada realizada pela empresa processadora junto ao um corretor. Apenas 14\% da empresas processadoras da amostra indicaram que não realizam compra antecipada. A empresa processadora oferece um adiantamento de capital, que deve ser pago com a entrega de castanha na semana seguinte. Segundo todos os corretores entrevistados, o preço é fixado no início da transação. Durante o período de uma semana, o corretor irá formar o estoque necessário para a liquidação. $\mathrm{O}$ risco de alterações de preço durante esse período é assumido pelo corretor.

Assim como as empresas processadoras adiantam recursos semanais para os corretores, esses últimos adiantam recursos para os produtores. Portanto, a 
maior parte do capital de giro necessário para levar a castanha em casca do produtor até a empresa processadora é fornecida por essa última (Figura 3). De fato, é esse capital que, injetado na cadeia, coloca em movimento parcela significativa da castanha em casca comercializada. Isso significa que o corretor tem a possibilidade de obter ganhos excepcionais, sem capital de giro próprio, operando com grandes volumes. Por exemplo, um grande corretor, negociando 12 "carradas" por dia nos dois meses de pico da safra, pode obter uma margem líquida, em 40 dias úteis, de $\mathrm{R} \$ 480$ mil sem operar com estoques especulativos e trabalhando apenas com capital adiantado por grandes empresas processadoras.

\subsection{Outras atividades dos corretores}

Os corretores possuem outras atividades, sendo a mais visível o comércio atacadista/varejista (5 dos 9 corretores tinham algum tipo de comércio). A atividade comercial está associada ao próprio mecanismo de comercialização de castanha. Nesse caso, tanto grandes quanto médios e pequenos corretores possuem pontos de venda de gêneros demandados pelos produtores rurais e outros consumidores. Nesses pontos de comercialização são administradas tanto as transações com castanha em casca quanto as com outros gêneros. De fato, um volume significativo de castanha é comprado por meio de transações casadas com a venda de gêneros de primeira necessidade. Os corretores fornecem esses gêneros aos produtores por um período que pode alcançar até 10 meses antes do início da colheita, para pagamento com a entrega de castanha em casca na época da colheita. Grandes corretores operam também como atacadistas nessas transações, vendendo a prazo para os corretores/ varejistas menores (bodegueiros), que por sua vez também realizam o pagamento com entrega de castanha no período de colheita (Figura 4).

As operações de venda a prazo, além de constituírem uma fonte adicional de renda para corretores/atacadistas/varejistas, pois são pagos juros e obtém-se margens sobre os gêneros transacionados, são também um instrumento utilizado para obter fidelização. Entretanto, qualquer fidelização assim construída ao longo da rede pode romper-se em momentos de escassez de oferta, quando se acirra a concorrência por castanha; embora seja reconstruída em anos normais ou de oferta abundante.

As atividades comerciais associadas às transações com castanha em casca permitem aos corretores obter não apenas uma margem sobre a intermediação de castanha mas também uma margem sobre o produto que é pago com a entrega da castanha, além dos juros explícitos ou embutidos no preço dos gêneros. Essas transações casadas conferem a esses agentes um enorme poder de mercado diante de um concorrente que não as estabeleça, mesmo que esse último ofereça melhores preços, com pagamento à vista. $\mathrm{O}$ comerciante/varejista estará em boas condições para suportar uma guerra de preços dado que sua margem total (operando no varejo de gêneros de primeira necessidade, na comercialização de castanha e na operação de crédito) será maior do que a do entrante, que obtém margem apenas com as operações com castanha.

As operações de compra de castanha associadas ao comércio varejista do corretor e à prática de concessão de crédito para custeio não estabelecem apenas um vínculo financeiro/comercial entre corretores e produtores mas também relações pessoais. $\mathrm{O}$ corretor, como um agenciador de microcrédito para tomadores, apóia-se em instrumentos culturais (reputação e confiança) presentes em estruturas híbridas de governança (MÉNARD, 2004), algo que um banco comercial tradicional dificilmente é capaz de estabelecer. $\mathrm{O}$ corretor procurará fortalecer essas relações com objetivo de fidelizar os produtores. Registre-se que parte dos produtores rurais não dispõem da alternativa de recorrer ao mercado bancário de crédito, dado que não possuem garantias para oferecer às instituições financeiras.

\subsection{Principais condicionantes da compra antecipada}

A compra antecipada é a transação tradicional que governa a gestão de suprimento de castanha em casca nas grandes empresas processadoras. Esse tipo de compra é resultado de dois condicionantes

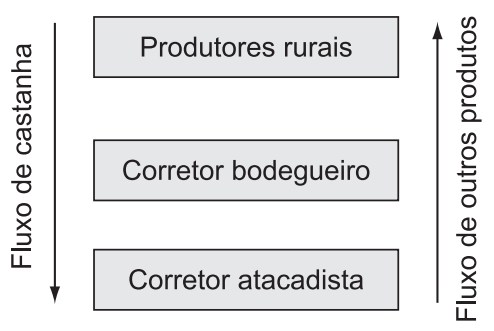

Figura 4. Fluxo de castanha e outros produtos entre corretores e produtores rurais.
Figura 3. Fluxo de castanha e crédito entre produtores rurais, corretores e empresas processadoras. 
fundamentais: a herança histórica de laços de dependência entre corretores locais e produtores rurais e a necessidade de grandes estoques operacionais. As relações de dependência estabelecidas entre produtores rurais pobres e corretores é herança do auge da cultura do algodão, que predominou no Ceará no século XIX. Esse padrão se reproduz nas relações entre produtores rurais, corretores e processadores de castanha-de-caju. Embora o acesso dos produtores rurais ao crédito oficial barato tenha sido ampliado por meio do Programa Nacional de Fortalecimento da Agricultura Familiar, Fundo Constitucional do Nordeste e outros programas, ainda é grande o número daqueles que não têm acesso a esses recursos. Mesmo aqueles produtores que têm acesso ao crédito oficial (41\% dos produtores da amostra) continuam a tomar também o crédito adicional fornecido por meio de transações com castanha. Isso se deve não apenas à carência de recursos desses produtores mas também às condições de operação do crédito bancário oficial, mais burocrático, condicionado à apresentação de garantias e que nem sempre atende às necessidades do produtor no momento em que ele mais necessita; algo que os corretores sabem fazer com maestria. Adiciona-se ainda o fato de que a inadimplência nos programas de crédito oficial tem aumentado, impedindo novos acessos dos devedores $(41 \%$ dos produtores da amostra declararam-se impossibilitados de tomar crédito).

O segundo condicionante da compra antecipada está na necessidade de as empresas processadoras assegurarem um volume substancial de castanha em condições de oferta de matéria-prima escassa e concentrada no tempo. As unidades processadoras operam durante todo o ano, parando apenas se ocorrer falta não planejada de castanha em casca, como no ano de 2008. De fato, há elevado investimento em capital fixo nas grandes unidades de processamento que operam no Brasil, o que é determinado pela elevada escala de operação e pelo processo mecanizado largamente adotado. Além disso, as unidades de processamento não têm uso alternativo, conforme declarado por todas as empresas entrevistadas; ou seja, são ativos dedicados exclusivamente à produção de ACC. Nessas condições, a falta de castanha em casca paralisa as atividades e eleva substancialmente os custos com o capital fixo. Assim, para não correr o risco de depender dos estoques especulativos dos corretores, nos poucos meses de colheita as empresas compram grande volume de castanha. Trata-se de assegurar um estoque capaz de suprir o fluxo do processamento contínuo, que é determinado por uma oferta estável de ACC. Trata-se de viabilizar economicamente o investimento em ativos fixos dedicados ao processamento de uma matéria-prima cuja oferta é sazonal, algo típico de agroindústrias.
Com a demanda crescente no mercado de ACC e por outras castanhas, as empresas disputam fornecedores para atingir suas metas de estoque operacional. A principal arma de competição é muito mais a ampliação da oferta tradicional de adiantamentos aos corretores do que a guerra de preços.

\subsection{Barreiras a uma nova coordenação no mercado de castanha}

Conforme apresentado, os corretores são agentes de grande importância para a gestão de suprimento de castanha das empresas processadoras. De fato, os corretores realizam todas as operações logísticas necessárias para a captação de castanha junto a produtores com baixa escala de produção. Sua ação permite aumentar a escala de entrega, reduzindo os custos operacionais de recepção de matéria-prima e mesmo os custos de transação. Em outras palavras, caso as empresas processadoras optassem por comprar diretamente dos produtores, teriam que montar uma enorme estrutura física e administrativa para gestão de suprimentos (novos pontos descentralizados de coleta, contratação de funcionários, gestão de transporte e gestão de uma carteira ampla de fornecedores). Esse tipo de estrutura poderia resultar em ganhos de qualidade e redução das margens de intermediação. Entretanto, os custos operacionais e os custos de transação aumentariam. Como há grande incerteza quanto aos custos e resultados e, portanto, quanto ao retorno dessa nova estrutura, as empresas processadoras têm adotado uma estratégia cautelosa no teste de novas formas de coordenação.

Nesse sentido, algumas iniciativas têm sido tomadas, tais como contratação de agente local exclusivo para compra de castanha; construção de central de recebimento localizada em zona de concentração de produtores de castanha de boa qualidade; ofertas de compra junto a associações de produtores e assentamentos da reforma agrária; concurso para premiação de produtores; palestras para corretores e produtores, contratação de agente para identificar novos fornecedores; e criação de empresa âncora de porte médio capaz de comprar castanha diretamente de pequenos produtores localizados próximo à fábrica. A maioria das empresas ainda continua dependente dos corretores para comprar grandes volumes de castanha, seja com pagamento a vista seja com adiantamento de recursos, sustentando a estrutura antiga que ela própria gostaria de substituir. Nas entrevistas, não raro os corretores eram considerados como "um mal necessário".

As barreiras a uma forma de governança híbrida mais eficiente podem também ser explicadas pelas próprias características da castanha em casca enquanto commodity: comercialização em mercado global e baixa especificidade de ativos envolvidos na produção 
rural e na comercialização. Seguindo a conceituação de Williamson (1996), pode-se afirmar que a produção de castanha em casca possui baixa especificidade de ativos em termos temporais, locacionais e de ativos dedicados. A especificidade temporal baixa resulta do fato de a castanha em casca ser um produto de perecibilidade baixa, podendo ser estocada por até um ano, com custo reduzido, bastando para isso um depósito rudimentar. Os maiores custos estão relacionados à perda de peso (devida à perda de umidade) e ao custo de oportunidade do capital investido em estoques. A especificidade locacional baixa tem como determinante o reduzido custo de transporte, dado que não se exige qualquer tratamento especial para conservação nem investimento em veículos especiais. Isso permite que unidades processadoras em Fortaleza, por exemplo, possam ser abastecidas com castanhas trazidas de regiões produtoras de outros estados. Um corretor no Piauí não se obriga a vender para uma unidade de processamento local. A especificidade de ativo dedicado é também pequena. A comprovação disso está no fato de produtores e corretores não se obrigarem a vender castanha a um único comprador; não há fidelidade nas transações e dificilmente ela é imposta.

Poder-se-ia afirmar que a especificidade de ativos físicos no campo (destinados a um determinado fim) é elevada. Como em toda cultura permanente, os elevados investimentos iniciais de implantação da cultura devem ser recuperados em mais de um ciclo de produção. Todo esse capital, sob a forma de terra e plantas perenes, não tem uso econômico alternativo à produção de caju. A conversão de cajuais novos em outra atividade implicaria em perdas grandes. A implicação disso é que a implantação de cajuais novos exigiria o desenvolvimento de novas formas de coordenação que, por exemplo, premiassem volume e qualidade (NASSAR; MARINO; LEITE, 2000).

Entretanto, grande parte da produção atual de castanha ainda é proveniente de cajuais implantados há 20-30 anos. Por um lado, o valor do investimento realizado no passado para implantação desses cajuais não é contabilizado no cálculo econômico da maioria dos produtores; já estaria plenamente amortizado. Por outro, os gastos de custeio feitos pelos produtores nessas plantações são baixíssimos. Assim, a elevada especificidade de ativos físicos é relevante para as decisões de investimento em cajuais novos, notadamente aqueles mais intensivos em capital, mas é anulada no caso dos cajuais antigos.

A teoria sugere o mercado clássico como a melhor alternativa de governança para produtos com essas características. Ou seja, o mercado clássico apresenta menores custos de transação do que as formas híbridas. Mas nesse modelo, por exemplo, o uso de contratos de compra e venda que estabelecem compromissos de entrega e recebimento a preços e padrões de qualidade pré-estabelecidos enfrentaria dois importantes obstáculos. Em primeiro lugar, os custos da administração de milhares de contratos de baixo volume de castanha seriam elevados. Em segundo, a probabilidade de default (não cumprimento dos contratos) de ambas as partes diante de movimentos não previstos no preço da castanha também seria elevada: nem os processadores estariam dispostos a cumpri-los em caso de queda, nem os produtores, em caso de alta. A prova disso é a ausência de fidelidade nas transações quando ocorre escassez de produto: produtores e corretores vendem a quem oferece melhor preço, notadamente os médios e grandes produtores, que não dependem da oferta de crédito dos corretores.

Assim, a estratégia cautelosa das empresas processadores na implantação de uma nova estrutura de governança é, por um lado, racional diante do risco inerente às incertezas e, por outro, lenta diante das transformações do mercado internacional e do envelhecimento da base produtiva primária do país. O resultado é a perda de competitividade internacional, medida pela participação no mercado.

O controle absoluto da cadeia de suprimento pode ser alcançado por meio da integração vertical, ou seja, a forma hierárquica de coordenação. Algumas empresas processadoras nacionais possuem cajuais próprios para seu abastecimento. Entretanto, a produção própria de castanha em todas as empresas entrevistadas, com exceção de uma, encontrava-se abaixo de $1 \%$ do volume processado. Algumas empresas estavam investindo em aumento de produção própria, seja fazendo renovação de copas em cajuais antigos seja expandindo a área plantada. Outras rejeitam o investimento na ampliação de produção própria de castanha por considerarem que o retorno da atividade é baixo em grandes plantações, ou seja, não alcança a taxa mínima de atratividade exigida pelos grupos econômicos que controlam as maiores unidades de processamento. Da mesma forma em que há uma atitude cautelosa em relação às mudanças na tradicional cadeia de suprimento envolvendo corretores e produtores, há também uma atitude reservada em relação à expansão da verticalização. Haveria também alternativas mais rentáveis e de menor risco para o uso da terra em regiões de expansão da fronteira agrícola.

\section{Considerações finais}

O cultivo de caju e a extração e o processamento de castanha-de-caju são atividades tradicionais no Nordeste brasileiro. A extração e o processamento de castanha-de-caju são atividades com grande potencial de geração de renda e emprego, tanto na propriedade rural quanto nas agroindústrias. A castanha-de-caju representa uma das poucas cash crops que agricultores 
dispõem atualmente no Nordeste, especialmente no Piauí, Ceará e Rio Grande do Norte.

Apesar das vantagens de seu cultivo e processamento, a oferta de castanha-de-caju proveniente do Nordeste não tem se expandido na velocidade necessária para atender a demanda crescente por esse produto. Há restrições estabelecidas pela estrutura de governança da cadeia, que foram abordadas com maior detalhe nesse artigo, e há restrições tecnológicas, não abordadas aqui com profundidade. De fato, os cajuais antigos apresentam baixa produtividade e a variedade conhecida com cajueiro anão precoce, desenvolvida pela EMBRAPA, apesar de apresentar maior produtividade, está associada ao uso mais intensivo de insumos. Nesse sentido, muitos produtores ainda são resistentes à modernização, pois o diferencial de produtividade e a receita obtida não são atraentes.

Além das barreiras às novas formas de governança, há também outros fatores, não mencionados, que impedem transformações mais rápidas. Existe forte assimetria de informações entre produtores, corretores e empresas processadoras no que diz respeito às condições de mercado e preços, o que prejudica as negociações entre os atores da cadeia.

A existência de uma governança com baixo controle administrativo (por parte de empresas ou organizações) e poucos incentivos propicia a sobrevivência de intermediários, que movimentam expressivo volume de recursos. Trata-se de um processo ainda primitivo e informal, mas ainda necessário para garantir a oferta de matéria-prima para as empresas processadoras.

A pulverização dos produtores rurais e a baixa escala de produção dificultam a comercialização direta com as empresas processadoras. A existência dos corretores amplia essa dificuldade, dado o seu amplo conhecimento a respeito das condições de produção locais e da rede de produtores a eles ligados por relações de crédito e confiança. Essa rede opera como uma barreira à entrada de novos concorrentes.

Há iniciativas, ainda em estágio experimental, para ampliar transações diretas entre produtores e processadores. $\mathrm{Na}$ medida em que essas iniciativas demonstrarem vantagens, tanto para produtores quanto para processadores, assumirão maior dimensão enquanto forma de coordenação. Contratos formais dificilmente serão adotados entre empresas processadoras e pequenos produtores rurais nesse estágio inicial. Na medida em que avançar o aprendizado (learning by doing), bem como os laços de confiança, contratos de compra e venda deverão se difundir. Por enquanto, a intermediação por meio dos corretores é predominante e apresenta grande capacidade de reação à concorrência com as novas estruturas.

Assim, a velha estrutura apresenta resiliência e é uma concorrente forte. Pode oferecer maior rentabilidade para produtores rurais, que possuem pequena escala de produção e baixo nível tecnológico e, simultaneamente, preços mais baixos para os processadores. Entretanto, é incapaz de aumentar a oferta no volume e qualidade requeridos pelo mercado, o que, no médio e longo prazos, imporá problemas à continuidade da atividade.

A sobrevivência da atividade no Nordeste dependerá da articulação entre organizações de pesquisa, assistência técnica, crédito, capacitação e representação de classe para o estabelecimento de políticas públicas e estratégias privadas. As iniciativas que permitam introduzir alguma inovação no espaço de negociação dos produtores com as empresas processadoras são fundamentais. Por exemplo, as organizações de crédito poderiam fomentar empreendimentos vinculados à realização de transações diretas entre processadores e produtores, inclusive transações que possam ser formalizadas por meio de contratos que garantam prêmios por padrões de qualidade. Dessa forma, o crédito contribuiria não apenas para o aumento da escala de produção e nível tecnológico no campo mas também para o estabelecimento de formas mais eficientes de relações de mercado na cadeia. É importante que nessas novas relações sejam adotadas ferramentas de gestão capazes de melhorar a transmissão de informações e os estímulos à produção por qualidade e volume. Isso implica criar mecanismos que reduzam a assimetria de informações entre produtores, corretores e processadores, principalmente no que se refere à determinação de preços. Implica também no estabelecimento de acordos entre as organizações de classe para a implantação de um sistema de classificação e precificação da castanha em casca, bem como protocolos de procedimento para uma negociação anual de preço.

\section{Agradecimentos}

Este artigo apresenta resultados do estudo Cadeia Produtiva do Caju (PT 84), Projeto BRA/ IICA/03/008 - "Cooperação para o Fortalecimento da Capacidade Técnica, Institucional e Operacional do Banco do Nordeste".

\section{Referências bibliográficas}

BRASIL. Ministério da Agricultura, Pecuária e Abastecimento. Empresa Brasileira de Pesquisa Agropecuária. Embrapa Agroindústria Tropical; SERVIÇO BRASILEIRO DE APOIO ÀS MICRO E PEQUENAS EMPRESAS - SEBRAE. Castanha de Caju: iniciando um pequeno grande negócio agroindustrial: Brasília, DF: Embrapa Informação Tecnológica, 2003. (Série Agronegócios).

BRASIL. Ministério do Desenvolvimento, Indústria e Comércio Exterior - MDIC. Secretaria de Comércio Exterior - SECEX. ALICEWEb. Brasília, DF, 2008a. 
Disponível em: <http://aliceweb.desenvolvimento.gov. br>. Acesso em: 09 set. 2008.

BRASIL. Ministério do Planejamento, Orçamento e Gestão. Instituto Brasileiro de Geografia e Estatística - IBGE. Produção Agrícola Municipal - PAM. Brasília, DF, 2008b. Disponível em: <http://www.sidra.ibge.gov.br/ bda/pesquisas/pam>. Acesso em: 08 out. 2009.

COASE, R. H. The Nature of the Firm. Economica, v. 4, n. 16, p. 368-405, 1937.

COMTRADE - UNITED NATIONS COMMODITY TRADE STATISTICS DATABASE. Statistical database. International Merchandise Trade Statistics - IMTS. Disponível em: http://comtrade.un.org/db/. Acesso em: 08 setembro 2008.

FIGUEIRÊDO Jr., H. Desafios Para a Cajucultura no Brasil: o comportamento da oferta e da demanda da castanha de caju. Revista Econômica do Nordeste, v. 37, n. 4, p. 550-571, 2006.

GUANZIROLI, C. E.; CARDIM, S. E. C. S. (Coord.). Novo retrato da agricultura familiar: o Brasil redescoberto. Brasília, DF: INCRA/FAO, 2000. Disponível em: <http:// www.incra.gov.br/arquivos/0176102183.pdf>. Acesso em: 08 set. 2008.

HARILAL, K. N. et al. Power in Global Value Chains: Implications for Employment and Livelihoods in the Cashew Nut Industry in India. London: International Institute for Environment and Development - IIED, 2006.

IBGE - Instituto Brasileiro de Geografia e Estatísticas Censo Agropecuário 1995-1996. Disponível em: http:// www.sidra.ibge.gov.br/bda/pesquisas/ca/default1996. asp? $\mathrm{z}=\mathrm{p} \& \mathrm{o}=2 \& \mathrm{i}=\mathrm{P}$. Acesso em set. 2008.

INSTITUTO INTERAMERICANO DE COOPERAÇÃO PARA AGRICULTURA - IICA; BRASIL. Ministério da Fazenda. Banco do Nordeste do Brasil - BNB. Cadeia Produtiva do Caju. Projeto BRA/IICA/03/008 Cooperação para o Fortalecimento da Capacidade Técnica, Institucional e Operacional do Banco do Nordeste. Fortaleza, 2008.

KUMAR, K. (ed.) Rapid appraisal methods. Washington, D.C.: World Bank Regional and Sectorial Studies, 1993.
LEITE, L. A. S. A agroindústria do caju no Brasil: políticas públicas e transformações econômicas. Fortaleza: EMBRAPA-CNPAT, 1994. 195 p.

LEITE, L. A. S.; PAULA PESSOA, P. F. A. Estudo de cadeia produtiva como subsídio a pesquisa e desenvolvimento do agronegócio. Fortaleza: EMBRAPA-CNPAT, 1996.

MÉNARD, C. The economics of hybrid organizations. Journal of Institutional and Theoretical Economics, v. 160, p. 345-376, 2004.

NASSAR, A. M.; MARINO, M. K.; HERRMANN, I. Desafios para a Coordenação do SAG do Caju no Maranhão. In: SEMINÁRIO BRASILEIRO DA NOVA ECONOMIA INSTITUCIONAL, 2., 2001, Campinas. Anais... Campinas: UNICAMP, 2001.

NASSAR, A. M.; MARINO, M. K.; LEITE, L. A. S. Irmãos Fontenele: Liderança na Exportação de Castanha de Caju. In: SEMINÁRIO PENSA DE AGRIBUSINESS, 10., 2000, São Paulo. Anais... Disponível em: <http:// www.pensa.org.br/anexos/biblioteca/2212008112026_ EC00_Fontenele.pdf>. Acesso em: 10 out. 2008.

NORTH, D. Custos de Transação, Instituições e Desempenho Econômico. Rio de Janeiro: Instituto Liberal, 1994. 38 p.

SOUZA FILHO, H. M.; BUAINAIN, A. M.; GUANZIROLI, C. Metodologia para Estudo das Relações de Mercado em Sistemas Agroindustriais. Brasília: IICA, 2007.

SOUZA FILHO, H. M.; SILVA, C. A. Guidelines for rapid appraisal of agrifood chain performance in developing coutries. Roma: Food and Agriculture Organization of The United Nations, 2007.

WILLIAMSON, O. E. Comparative Economic Organization: The Analysis of Discrete Structural Alternatives. Administrative Science Quarterly, v. 36, n. 2, p. 269-296, 1991.

WILLIAMSON, O. E. The economic institutions of capitalism - firms, markets, relational contracting. New York: The Free Press, 1985. 468 p.

WILLIAMSON, O. E. The Mechanisms of Governance. Oxford: Oxford University Press, 1996. 